\title{
Antimicrobial Activity of Ethanolic and Methanolic Extracts of Urtica dioica, Mentha longifolia, and Bacteriocin Produced by Lactobacillus casei Against Antibiotic-resistant Bacteria
}

\author{
Masoumeh Kiani' $^{1}$ (D, Abazar Pournajaf ${ }^{2,3}$ (D), Thelma Zareh ${ }^{4}$ (D, Mohsen Karami $^{2,5}$ (D, Mojtaba Taghizadeh Armaki ${ }^{2,5}$ (D), Mehrdad Gholami ${ }^{6^{*}}$ (iD) \\ 1. Department of Microbiology, Faculty of Medicine, Shahid Sadoughi University of Medical Sciences, Yazd, Iran. \\ 2. Infectious Diseases and Tropical Medicine Research Center, Health Research Center, Babol University of Medical Sciences, Babol, Iran \\ 3. Department of Microbiology, Faculty of Medicine, Babol University of Medical Sciences, Babol, Iran. \\ 4. Business school, University of Surrey, Guildford, United Kingdom. \\ 5. Department of Medical Parasitology and Mycology, School of Medicine, Babol University of Medical Sciences, Babol, Iran. \\ 6. Department of Microbiology and Virology, Faculty of Medicine, Mazandaran University of Medical Sciences, Sari, Iran.
}

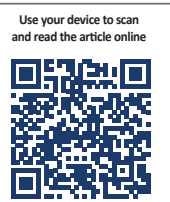

Citation Kiani M, Pournajaf A, Zareh T, Karami M, Taghizadeh Armaki M, Gholami M. Antimicrobial Activity of Ethanolic and Methanolic Extracts of Urtica dioica, Mentha longifolia, and Bacteriocin Produced by Lactobacillus casei Against Antibiotic-resistant Bacteria. Research in Molecular Medicine. 2020; 8(4):163-170. https://doi.org/10.32598/rmm.8.1062.2

https://doi.org/10.32598/rmm.8.1062.2

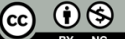

Article Type:

Research Paper

Article info:

Received: 06 Sep 2020

Revised: 30 Sep 2020

Accepted: 24 Oct 2020

Keywords:

Lactobacillus casei, Urtica dioica, Mentha longifolia, Methanolic, Antibiotic-resistant :

\section{A B S T RA C T}

Background: The increasing resistance of human microbial pathogens to the available antibacterial compounds is a significant threat, resulting in the search for new antibiotic resources such as plants and probiotics. Therefore, this study aimed to evaluate the antibacterial effect of ethanolic and methanolic extracts of Urtica dioica, Mentha longifolia, and bacteriocin purified from a probiotic bacteria using the standard disk diffusion method against some pathogenic strains.

Materials and Methods: Ethanolic/methanolic extract of U. dioica, M. longifolia, and bacteriocin from probiotic bacteria were prepared by the standard methods. The effect of different concentrations of the extracts on some antibiotic-resistant bacteria was evaluated using the standard disk diffusion method by measuring the diameter of the growth inhibition zone.

Results: The disk diffusion test showed that the bacteriocin Lactobacillus casei had more growth inhibitory effects on the tested bacterial strains than the methanolic and ethanolic extracts of $U$. dioica and $M$. longifolia. Bacteriocin extract of $L$. casei exhibited significant antibacterial activity at the concentrations of 12 and $18 \mathrm{mg} / \mathrm{mL}(\mathrm{P} \leq 0.05)$ against antibiotic-resistant bacteria, while a $12 \mathrm{~mm}$ zone of inhibition was observed in the concentration of $1.5 \mathrm{mg} / \mathrm{mL}$ against Salmonella enterica serovar Typhimurium (S. Typhimurium).

Conclusion: According to the agar well diffusion method results, the bacteriocin producing $L$. casei has an extensive range of antibacterial spectrum against resistant bacteria. It can be used as an alternative to antimicrobia agents for the treatment of infections caused by resistant bacteria. It is suggested that in future research, the cytotoxicity of the extracts be evaluated in vitro/in vivo studies.

\footnotetext{
* Corresponding Author:

Mehrdad Gholami, PhD.

Address: Department of Microbiology and Virology, Faculty of Medicine, Mazandaran University of Medical Sciences, Sari, Iran.

Phone: +98 (11) 33543081

E-mail:mehrdad_gholami90@yahoo.com
} 


\section{Introduction}

A

lthough pharmacological activities have introduced and produced several new antibiotics in the last couple of decades, resistance to this antibiotic by human pathogenic bacteria has increased [1-3]. Overall, pathogenic bacteria have the genetic capability to acquire and transmit resistance to these antibiotics, which are used for therapeutic purposes [4, 5]. Nowadays, medicinal herbal plants and probiotic production of bacteria have many applications in human infections [6]. People in Asia, Africa, and Latin America use plants as a form of medication which accounts for approximately $80 \%$ of the world use old-fashioned health therapies and they are described to have the least side effects [7]. Two of these herbal plants, i.e. U. dioica and $M$. longifolia are often used therapeutically as a traditional treatment for different diseases. $U$. dioica with the Latin name nettle is a member of the Urticaceae class and has many significant purposes in ancient therapy due to it having various remediable effects $[8,9]$.

M. longifolia (Family: Lamiaceae, Class: Magnoliopsida) is an important herbal plant in the traditional system of Ayurveda used for the treatment of several chronic diseases and is widely scattered in India, Pakistan, Sri Lanka, Iraq, Iran, Turkey, Egypt, Greece, China, and Mediterranean areas $[10,11]$. Several studies have reported that $M$. longifolia and $U$. dioica have an excellent antimicrobial effect against different pathogenic bacteria [11-16]. Besides, probiotic Lactic Acid Bacteria (LAB) such as L. casei, Lactobacillus gasseri, Lactobacillus acidophilus, Lactobacillus johnsonii, Lactobacillus rhamnosus, and Lactobacillus reuteri are the most common strains of microbes used as probiotics [17]. These bacteria can produce different antimicrobial components, including organic acids, low-molecular-weight antimicrobial substances, and bacteriocins [18]. The probiotic bacteria such as L. acidophilus and Bifidobacterium spp. are increasingly used in pharmaceutical applications and they have excellent therapeutic benefits [19]. Amin et al. indicated that the isolation of 60 LAB strains from vegetables in MRS broth medium (Man-RogosaSharpe) showed significant antibacterial activity against pathogenic bacteria such as Escherichia coli, Shigella dysenteriae, Salmonella typhi, Staphylococcus aureus, and Bacillus anthracis [20]. It is essential to focus on the substitution sources of the antimicrobial agents as the pathogenic microorganism is acquisition resistance against usual antibiotics [21]. Medicinal plants such as Ocimum gratissimum, Vernonia amygdalina, and Aframomum melegueta have been ascertained to provide various culinary and medicinal properties. These medicinal properties exert bacteriostatic and bactericidal effects on some bacteria $[21,22]$. This in vitro study aimed to determine the antimicrobial effect of $U$. dioica and M. longifolia, and antimicrobial properties of selected probiotic bacteria (L. casei).

\section{Materials and Methods}

\section{Plant Collection}

U. dioica was collected from Lahijan City and M. longifolia was collected from the Zabol City. Samples were collected from May to June of 2015.

\section{Extract Preparation}

The aerial fragments of $U$. dioica and M. longifolia were shade-dried at room temperature for 15 days and then ground to a fine powder using an electronic blender. The extract was obtained from $1 \mathrm{~g}$ of the powder using $10 \mathrm{~mL}$ of alcohol (ethanol or methanol) (Merck, Germany) and distilled water solu-tion, centrifugation at $3000 \mathrm{rpm}$ for 15 minutes, and collecting the supernatant. This procedure was repeated three times and the solvents were evaporated by placing the yielded materials at room temperature for 7 days [23, 24].

\section{Bacterial Strains}

In this experimental study, the following American Type Culture Collection (ATCC) strains of bacteria were used: methicillin-resistant Staphylococcus aureus ATCC 43300, vancomycin-resistant Enterococcus faecalis ATCC 51299, carbapenem-resistant Pseudomonas aeruginosa ATCC 2113, carbapenem-resistant Acinetobacter baumannii ATCC 1605, carbapenem-resistant Klebsiella pneumoniae ATCC 1705, and clinical isolates of S. Typhimurium were obtained from the Medical Sciences Culture Collection in Tehran, Iran. By conventional microbiological and biochemical tests, the tested strains were identified. Antimicrobial susceptibility testing (AST) of the tested strains was re-checked using the Kirby-Bauer disk diffusion method as described by CLSI 2018 [25]. Also, L. casei ATCC 39392 as a probiotic strain was obtained from the Persian variety of the culture collection (Tehran, Iran).

\section{Production of crude bacteriocin}

To extract the bacteriocin, L. case $i$ was cultured in 250 $\mathrm{mL}$ of the MRS broth for $72 \mathrm{~h}$ at $30^{\circ} \mathrm{C}$ anaerobically. The supernatant was obtained through centrifugation at $10000 \mathrm{rpm}$ for $10 \mathrm{~min}$ and was adjusted to $\mathrm{pH}$ 7.0. Then, 
the supernatant was precipitated with $40 \%$ ammonium sulfate and the mixed reaction was rotated for $1 \mathrm{~h}$ and centrifuged at $10000 \mathrm{rpm}$ for 15 minutes. The precipitates were dialyzed and re-suspended in $10 \mathrm{~mL}$ of 0.05 $\mathrm{M}$ potassium phosphate buffer with $\mathrm{pH} 7.0$ [26].

\section{Antimicrobial Susceptibility Testing}

The antibacterial activities of the extracts and bacteriocin produced by $L$. casei were checked using the agar well diffusion method [27-29]. The test strains were grown on blood agar medium plates for $24 \mathrm{~h}$ at $37^{\circ} \mathrm{C}$. Single colonies from the strains were suspended in sterile Mueller- Hinton broth (Merck company, Darmstadt, Germany), and the turbidity was adjusted against 0.5 McFarland standard concentration $(1.5 \times 108 \mathrm{CFU} / \mathrm{mL})$. Then, the prepared suspension was inoculated on Mueller Hinton agar medium (Merck, Darmstadt, Germany). Blank disks $(6.4 \mathrm{~mm})$ were saturated by different doses of the extract $(1.5,3,6,12$, and $18 \mathrm{mg})$ were placed on lawn cultures after solvent evaporation. Then the plates were incubated for $24 \mathrm{~h}$ at $37^{\circ} \mathrm{C}[30,31]$. Each experiment was conducted three times to observe an effective outcome. Also, filter paper disks inoculated with sterile saline and fosfomycin were used as negative and positive control, respectively. The inhibition zone around each disk was measured in mm using a ruler [32].

\section{Statistical Analysis}

The Statistical Package for the Social Sciences (SPSS 20; SPSS Inc., Chicago, IL, USA) was used to study the differences between the means in the study parameters.
The results were considered significant when $\mathrm{P}$ values were less than 0.05 .

\section{Results}

The standard disk diffusion assay was done to determine the presence of antibacterial activities. The antimicrobial activity of ethanolic and methanolic extracts of $U$. dioica appeared as a growth inhibition factor for MRSA ATCC 43300 and VREF ATCC 51299; however, these two extracts of the $U$. dioica have minimal inhibition effect on CRPA ATCC 2113, CRAB ATCC 1605, and CRKP ATCC 1705. The results of the antimicrobial susceptibility of $U$. dioica are presented in Table 1 . The highest activity (inhibition zone diameter about $18 \mathrm{~mm}$ ) was demonstrated by the methanolic extract of $U$. dioica against VREF ATCC 51299 while the lowest activity (inhibition zone diameter about $4 \mathrm{~mm}$ ) was revealed by the ethanolic extract against CRAB ATCC 1605 and CRKP ATCC 1705. The antibacterial susceptibility of ethanolic and methanolic extracts of $M$. longifolia appeared to inhibit the growth of CRPA ATCC 2113, CRAB ATCC 1605, and CRKP ATCC 1705. However, these two extracts of $M$. longifolia has a minimal inhibition effect on MRSA ATCC 43300 and VREF ATCC 51299.

The results of the antimicrobial activity of $M$. longifolia are presented in Table 2. The highest activity (inhibition zone diameter about $19 \mathrm{~mm}$ ) was demonstrated by the methanolic extract of $M$. longifolia against CRPA ATCC 2113 while the lowest activity (inhibition zone diameter about $7 \mathrm{~mm}$ ) was demonstrated by the ethanolic

Table 1. Antibacterial activity of the ethanolic and methanolic extracts of $U$. dioica against pathogenic bacteria

\begin{tabular}{|c|c|c|c|c|c|c|c|c|c|c|}
\hline \multirow{4}{*}{ Organisms } & \multicolumn{10}{|c|}{ Mean Zones of Inhibition ( $\mathrm{mm}$ ) } \\
\hline & \multicolumn{10}{|c|}{ Concentration of Extract $(\mathrm{mg} / \mathrm{mL})$} \\
\hline & \multicolumn{5}{|c|}{ Ethanolic Extract } & \multicolumn{5}{|c|}{ Methanolic Extract } \\
\hline & 18 & 12 & 6 & 3 & 1.5 & 18 & 12 & 6 & 3 & 1.5 \\
\hline MRSA ATCC 43300 & 14 & 12 & 10 & 8 & 7 & 16 & 15 & 12 & 11 & 9 \\
\hline VREF ATCC 51299 & 17 & 15 & 13 & 12 & 11 & 18 & 15 & 12 & 10 & 8 \\
\hline CRPA ATCC 2113 & 11 & 9 & 8 & 7 & 6 & 13 & 11 & 10 & 9 & 8 \\
\hline CRAB ATCC 1605 & 12 & 8 & 7 & 4 & No effect & 11 & 9 & 8 & No effect & No effect \\
\hline CRKP ATCC 1705 & 11 & 9 & 6 & 4 & No effect & 12 & 10 & 9 & No effect & No effect \\
\hline S. Typhimurium & No effect & No effect & No effect & No effect & No effect & No effect & No effect & No effect & No effect & No effect \\
\hline
\end{tabular}

Methicillin-resistant Staphylococcus aureus (MRSA); Vancomycin-resistant Enterococcus faecium (VREF); Carbapenem-resistant Pseudomonas aeruginosa (CRPA); Carbapenem-resistant Acinetobacter baumannii (CRAB); Carbapenem-resistant Klebsiella pneumoniae (CRKP) 
Table 2. Antibacterial susceptibility of the ethanolic and methanolic extracts of M. longifolia against pathogenic bacteria

\begin{tabular}{|c|c|c|c|c|c|c|c|c|c|c|}
\hline \multirow{4}{*}{ Organisms } & \multicolumn{10}{|c|}{ Mean Zones of Inhibition (mm) } \\
\hline & \multicolumn{10}{|c|}{ Concentration of Extract (mg/mL) } \\
\hline & \multicolumn{5}{|c|}{ Ethanolic Extract } & \multicolumn{5}{|c|}{ Methanolic Extract } \\
\hline & 18 & 12 & 6 & 3 & 1.5 & 18 & 12 & 6 & 3 & 1.5 \\
\hline MRSA ATCC 43300 & 8 & 7 & No effect & No effect & No effect & 9 & 6 & No effect & No effect & No effect \\
\hline VREF ATCC 51299 & 11 & 7 & No effect & No effect & No effect & 10 & 7 & No effect & No effect & No effect \\
\hline CRPA ATCC 2113 & 17 & 14 & 12 & 11 & 9 & 19 & 17 & 16 & 15 & 12 \\
\hline CRAB ATCC 1605 & 16 & 14 & 11 & 9 & 7 & 18 & 17 & 14 & 12 & 11 \\
\hline CRKP ATCC 1705 & 18 & 16 & 14 & 13 & 11 & 16 & 15 & 13 & 10 & 9 \\
\hline S. Typhimurium & No effect & No effect & No effect & No effect & No effect & No effect & No effect & No effect & No effect & No effect \\
\hline
\end{tabular}

Methicillin-resistant Staphylococcus aureus (MRSA); Vancomycin-resistant Enterococcus faecium (VREF); Carbapenem-resistant Pseudomonas aeruginosa (CRPA); Carbapenem-resistant Acinetobacter baumannii (CRAB); Carbapenem-resistant Klebsiella pneumoniae (CRKP)

Table 3. Antibacterial activity of L. casei purified bacteriocin against pathogenic bacteria

\begin{tabular}{|c|c|c|c|c|c|}
\hline \multirow{3}{*}{ Organisms } & \multicolumn{5}{|c|}{ Mean Zones of Inhibition (mm) } \\
\hline & \multicolumn{5}{|c|}{ Concentration of purified bacteriocin $(\mathrm{mg} / \mathrm{mL})$} \\
\hline & 1.5 & 3 & 6 & 12 & 18 \\
\hline MRSA ATCC 43300 & 21 & 20 & 19 & 18 & 17 \\
\hline VREF ATCC 51299 & 24 & 20 & 16 & 15 & 14 \\
\hline CRPA ATCC 2113 & 22 & 20 & 18 & 16 & 14 \\
\hline CRAB ATCC 1605 & 18 & 17 & 16 & 15 & 13 \\
\hline CRKP ATCC 1705 & 13 & 12 & 11 & 9 & 7 \\
\hline S. Typhimurium & 12 & 11 & 9 & 8 & 6 \\
\hline
\end{tabular}

Methicillin-resistant Staphylococcus aureus (MRSA); Vancomycin-resistant Enterococcus faecium (VREF); Carbapenem-resistant Pseudomonas aeruginosa (CRPA); Carbapenem-resistant Acinetobacter baumannii (CRAB); Carbapenem-resistant Klebsiella pneumoniae (CRKP)

extract against CRAB ATCC 1605. On the other hand, the bacteriocin extracts of $L$. case $i$ were more active against 4 strains of MRSA ATCC 43300, VREF ATCC 51299, CRPA ATCC 2113, and CRAB ATCC 1605. The highest activity (inhibition zone diameter about $19 \mathrm{~mm}$ ) was demonstrated by the bacteriocin extracts of $L$. $c a$ sei against VREF ATCC 51299, while the lowest activity (inhibition zone diameter about $6 \mathrm{~mm}$ ) was demonstrated by the bacteriocin extracts of $L$. casei against $S$. Typhimurium (Table 3).

\section{Discussion}

Although the treatment of microbial infections with antibiotics seems harmless and effective, it has various problems. It has become evident that antibacterial resistance has increased and thus the development of new antibacterial agents is undoubtedly required [33]. In the current study, several resistant bacterial strains were selected to examine the antimicrobial effects of ethanolic and methanolic extracts of the $U$. dioica and $M$. longifolia. In addition to this, the antibacterial activity of bacteriocin $L$. casei was evaluated against resistant bacterial strains. Several scientists have analyzed and described 
the antimicrobial activities of various plants [34, 35]. In ancient treatment, $U$. dioica has been identified for its several therapeutic properties such as cardiovascular [36], anti-rheumatic, anti-inflammatory [24, 37], acute diuretic effects, hypotensive, and natriuretic [8].

Gulcin et al. reported that the antimicrobial activity of the water extract of $U$. dioica against $P$. aeruginosa ATCC 9027, E. coli ATCC 9837, S. aureus ATCC 6538, and S. pneumoniae ATCC 49619 [9]. Our results were similar to the findings of Gulcin et al. [9] and all bacteria have been inhibited by the $U$. dioica plant extract. Ibrahim et al. reported that the botanical extract of the $U$. dioica significantly inhibited the cell growth of MRSA [38]. Heidary et al. reported that the extracts of the $U$. dioica had high [34, 35] antibacterial effects against $\beta$-lactamase producing $P$. aeruginosa [39].

According to our results, butanol ethanolic and methanolic extracts of $U$. dioica can inhibit MRSA strains. Also, ethanolic and methanolic extracts of the $U$. dioica could inhibit some resistant strains. This antibacterial activity may be related to alkaloid, tannins, terpenes glycosides and phenol components that were present in nettle [16]. S. Typhimurium was resistant to ethanolic and methanolic extracts of the $U$. dioica. $M$. longifolia is an aromatic stimulant used for alleviating nausea, vomiting, and headaches. In the study of Bakht, all extracts from M. longifolia displayed different ranges of antibacterial activities [40].

Hajlaoui et al. reported that the essential oil of M. longifolia ssp. longifolia has great antimicrobial activity potential against $S$. epidermidis CIP 106510, S. aureus ATCC 25923, Micrococcus luteus NCIMB 8166, E. coli ATCC 35218, Listeria monocytogenes ATCC 19115, E. faecalis ATCC 29212, P. aeruginosa ATCC 27853 and S. Typhimurium LT2 DT104 [41]. Gulluce et al. exhibited a strong antibacterial activity of the M. longifolia L. ssp. Longifolia oil against various microorganisms [11]. Our outcomes determine that ethanolic and methanolic extracts have a stronger and wider spectrum of antibacterial activity against resistant bacteria. These results were in accordance with those reported by Gulluce et al. [11]. S. Typhimurium was resistant to both ethanolic and methanolic extracts of $M$. longifolia. Furthermore, L. casei produced bacteriocin that was active against the resistant strains used in the current study.

Prema et al. reported that the bacteriocin-producing strain, L. plantarum displayed that the inhibitory zone ranged from $16 \mathrm{~mm}$ to $24 \mathrm{~mm}$ against $E$. coli, Salmonella typhi, Vibrio cholerae, and S. dysenteriae [42]. Venkate- san et al. isolated probiotic organisms, Bifidobacterium spp. and Lactobacillus spp. from soil and curd. Then, probiotic Bifidobacterium spp. displayed high inhibitory effect against Salmonella spp. [43]. In the present study, the maximum zone of inhibition (24 $\mathrm{mm}$ ) was recorded against VREF ATCC 51299 as an indicator strain. Followed by this, $22 \mathrm{~mm}, 21 \mathrm{~mm}$, and $18 \mathrm{~mm}$ were recorded against CRPA ATCC 2113, MRSA ATCC 43300, and CRAB ATCC 1605, respectively. In contrast, ethanolic and methanolic extracts $M$. longifolia and $U$. dioica, the bacteriocin of $L$. casei could inhibit the growth of $S$. Typhimurium. In total, the bacteriocin of $L$. casei is more effective than the alcoholic extracts of $M$. longifolia and $U$. dioica against 6 strains.

Badirzadeh reported that $U$. dioica extracts present promising antiparasitic activity and can be considered as an effective and harmless herbal material [44]. Sura et al. [45] investigated the antimicrobial activities of aquatic extracts of $U$. dioica by disk diffusionmethod. Their ren sults showed that all the extracts can be used more safely in the treatment of digestive diseases. The present study had some limitations, the minimum inhibitory concentration (MIC) and minimum bactericidal concentrations (MBC) tests was not performed to all the tested strains in line with the agar disk-diffusion method. Also, our research only focused on references strains, and antimicrobial activities of these extracts on multidrug-resistant (MDR), extensively drug-resistant (XDR) and pandrugresistant (PDR) bacteria recovered from the patients was not evaluated. In order to achieve better results, MTT assay to evaluate the cytotoxic potential of the extracts is also necessary.

The study assessed the effectiveness and antimicrobial influence of the selected probiotic strains and ethanolic and methanolic extracts of $U$. dioica, M. longifolia extract on antibiotic-resistant bacteria. The outcomes of this work can run some elucidations on the traditional application of effective substances of the plants tested to combat infections caused by bacteria, particularly those caused by resistant pathogens. However, more in vitro as well as in vivo studies should be carried out to gain further insight on the effect and doses of these compounds required to effectively manage bacterial resistance. As displayed through the data, the bacteriocin producing L. casei has a wide range of the antibacterial spectrum against resistant bacteria. 


\section{Ethical Considerations}

\section{Compliance with ethical guidelines}

There were no ethical considerations to be considered in this research.

\section{Funding}

This research did not receive any grant from funding agencies in the public, commercial, or non-profit sectors.

\section{Authors' contributions}

Supervision: Abazar Pournajaf, Mehrdad Gholami; Data collection: Masoumeh Kiani and Mohsen Karami; Data analysis: Mojtaba Taghizadeh Armaki and Thelma Zareh; Writing - original draft: Mehrdad Gholami and Abazar Pournajaf.

\section{Conflict of interest}

The authors declared no competing interests

\section{Acknowledgements}

We would like to gratefully acknowledge Dr. Ramazan Rajabnia for his technical assistance.

\section{References}

[1] Piddock LJ. Understanding drug resistance will improve the treatment of bacterial infections. Nat Rev Microbiol 2017; 15(11):639-40. [DOI:10.1038/nrmicro.2017.121] [PMID]

[2] Gupta R, Malik A, Rizvi M, Ahmed M, Singh A. Epidemiology of multidrug-resistant Gram-negative pathogens isolated from ventilator-associated pneumonia in ICU patients. J Glob Antimicrob Resist. 2017; 9:47-50. [DOI:10.1016/j.jgar.2016.12.016] [PMID]

[3] Livermore DM. Bacterial resistance: Origins, epidemiology, and impact. Clin Infect Dis. 2003; 36(Supplement 1):S11-S23. [DOI:10.1086/344654] [PMID]

[4] Alanis AJ. Resistance to antibiotics: Are we in the postantibiotic era? Clin Infect Dis. 2005; 36(6):697-705. [DOI:10.1016/j.arcmed.2005.06.009] [PMID]

[5] Durrant W, Dong X. Systemic acquired resistance. Annu Rev Phytopathol. 2004; 42:185-209. [DOI:10.1146/annurev. phyto.42.040803.140421] [PMID]

[6] Rios J, Recio M. Medicinal plants and antimicrobial activity. J Ethnopharmacol. 2005; 100(1):80-4. [DOI:10.1016/j. jep.2005.04.025] [PMID]
[7] Doughari J. Antimicrobial activity of Tamarindus indica Linn. Trop J Pharm Res. 2007; 5(2):597-603. [DOI:10.4314/ tjpr.v5i2.14637]

[8] Tahri A, Yamani S, Legssyer A, Aziz M, Mekhfi H, Bnouham $\mathrm{M}$, et al. Acute diuretic, natriuretic and hypotensive effects of a continuous perfusion of aqueous extract of Urtica dioica in the rat. J Ethnopharmacol. 2000; 73(1):95-100. [DOI:10.1016/S0378-8741(00)00270-1]

[9] Gülçin I, Küfrevioğlu Öİ, Oktay M, Büyükokuroğlu ME. Antioxidant, antimicrobial, antiulcer and analgesic activities of nettle (Urtica dioica L.). J Ethnopharmacol. 2004; 90(2):205-15. [DOI:10.1016/j.jep.2003.09.028] [PMID]

[10] Jena V, Gupta S, Patel K, Patel S. Evaluating heavy metals contents in medicinal plant mentha longifolia. JChinese Chem Soc. 2007; 54:339-43. [DOI:10.1002/jccs.200700049]

[11] Gulluce M, Sahin F, Sokmen M, Ozer H, Daferera D, Sokmen A, et al. Antimicrobial and antioxidant properties of the essential oils and methanol extract from Mentha longifolia L. ssp. longifolia. Food Chem. 2007; 103(4):1449-56. [DOI:10.1016/j.foodchem.2006.10.061]

[12] Mimica-Dukić N, Bozin B, Soković M, Mihajlović B, Matavulj M. Antimicrobial and antioxidant activities of three Mentha species essential oils. Planta Med. 2003; 69(5):4139. [DOI:10.1055/s-2003-39704] [PMID]

[13] Mkaddem M, Bouajila J, Ennajar M, Lebrihi A, Mathieu F, Romdhane M. Chemical composition and antimicrobial and antioxidant activities of Mentha (longifolia L. and viridis) essential oils. J Food Sci. 2009; 74(7):M358-M63. [DOI:10.1111/j.1750-3841.2009.01272.x] [PMID]

[14] Turker A, Usta C. Biological screening of some Turkish medicinal plant extracts for antimicrobial and toxicity activities. Nat Prod Res. 2008; 22(2):136-46. [DOI:10.1080/14786410701591663] [PMID]

[15] Modarresi-Chahardehi A, Ibrahim D, Fariza-Sulaiman S, Mousavi L. Screening antimicrobial activity of various extracts of Urtica dioica. Revista de Biología Tropical. 2012 60(4):1567-76. [DOI:10.15517/rbt.v60i4.2074] [PMID]

[16] Ghaima KK, Hashim NM, Ali SA. Antibacterial and antioxidant activities of ethyl acetate extract of nettle (Urtica dioica) and dandelion (Taraxacum officinale). J Appl PharmSci. 2013; 3(5):96. https://www.researchgate.net/ publication/288417502

[17] Walter J. Ecological role of lactobacilli in the gastrointestinal tract: Implications for fundamental and biomedical research. Appl Environ Microbiol. 2008; 74(16):4985-96. [DOI:10.1128/ AEM.00753-08] [PMID] [PMCID]

[18] Tenea GN, Yépez L. Bioactive compounds of lactic acid bacteria. Case study: Evaluation of antimicrobial activity of bacteriocin-producing lactobacilli isolated from native ecological niches of Ecuador. Probiot Prebiot Hum Nutr Health. 2016:149-67. [DOI:10.5772/63112] [PMID]

[19] Kailasapathy K, Chin J. Survival and therapeutic potential of probiotic organisms with reference to Lactobacillus acidophilus and Bifidobacterium spp. Immunol Cell Biol. 2000; 78(1):80-8. [DOI:10.1046/j.1440-1711.2000.00886.x] [PMID]

[20] Amin M, Jorfi M, Khosravi A, Samarbafzadeh A, Sheikh AF. Isolation and identification of Lactobacillus casei and 
Lactobacillus plantarum from plants by PCR and detection of their antibacterial activity. Online J Biol Sci. 2009; 9(8):810-4. [DOI:10.3923/jbs.2009.810.814]

[21] Alo MN, Anyim C, Igwe JC, Elom M, Uchenna DS. Antibacterial activity of water, ethanol and methanol extracts of Ocimum gratissimum, Vernonia amygdalina and Aframomum melegueta. Adv Appl Sci Res. 2012; 3(2):8448. https://www.imedpub.com/articles/

[22] Akpoka OA, Okwu MU, Imade OS, Nwangwu SC, Omonegho E.g., Uti C. A Comparative Study of the Antibacterial Effect of Three Ethnomedical Plants (Ocimum gratissimum, Vernonia amygdalina and Cymbopogon citratus) on Certain Clinical Isolates. J Herb Med. 2019; 4(2). http://hmj.lums.ac.ir/index.php/hmj/article/view/751

[23] Seyyednejad M, Ebrahimzadeh H, Talaie A. Carbohydrate content in olive Zard $\mathrm{cv}$ and alternate bearing pattern. Int Sugar J. 2001; 103(1226):84-7. https://www.ree searchgate.net/publication/282738555

[24] Riehemann K, Behnke B, Schulze-Osthoff K. Plant extracts from stinging nettle (Urtica dioica), an antirheumatic remedy, inhibit the proinflammatory transcription factor NF-KB. FEBS Lett. 1999; 442(1):89-94. [DOI:10.1016/ S0014-5793(98)01622-6]

[25] Clinical and Laboratory Standards Institute. Performance standards for antimicrobial susceptibility testing; $25^{\text {th }}$ information supplement M100 [Internet]. 2015 [Cited Jun 2015 ]. Available from: http:// file.qums.ac.ir/repository/ mmrc/CLSI2015.pdf

[26] Ogunbanwo ST, Sanni AI, Onilude AA. Characterization of bacteriocin produced by Lactobacillus plantarum F1 and Lactobacillus brevis OG1. Afr J Biotechnol. 2003; 2(8):219-27. [DOI:10.5897/AJB2003.000-1045]

[27] Gram L, Melchiorsen J, Spanggaard B, Huber I, Nielsen TF. Inhibition of Vibrio anguillarum byPseudomonas fluorescens AH2, a Possible Probiotic Treatment of Fish. Appl Environ Microbiol. 1999; 65(3):969-73. [DOI:10.1128/ AEM.65.3.969-973.1999] [PMID] [PMCID]

[28] Tagg J, McGiven A. Assay system for bacteriocins. Appl Microbiol. 1971; 21(5):943. [DOI:10.1128/AEM.21.5.943943.1971] [PMID] [PMCID]

[29] Motamedi H, Seyyednejad SM, Bakhtiari A, Vafaei M. Introducing urtica dioica, a native plant of khuzestan, as an antibacterial medicinal plant. Jundishapur J Nat PharmProd. 2014; 9(4):e15904. [DOI:10.17795/jjnpp-15904] [PMID] [PMCID]

[30] Krishnaraju AV, Rao TV, Sundararaju D, Vanisree M, Tsay H-S, Subbaraju GV. Assessment of bioactivity of Indian medicinal plants using brine shrimp (Artemia salina) lethality assay. Int J Appl Sci Eng. 2005; 3(2):125-34 http://citeseerx.ist.psu.edu/viewdoc/download?doi=10. 1.1.613.7777\&rep=rep1\&type $=$ pdf

[31] Mahboobi M, Shahcheraghi F, Feizabadi MM. Bactericidal effects of essential oils from clove, lavender and geranium on multi-drug resistant isolates of Pseudomonas aeruginosa. Iran J Biotechnol. 2006; 4(2):137-40. https:/ / www.sid.ir/en/journal/JournalList.aspx?ID=2363

[32] Hussain A, Zaman M, Ramteke A. Antibacterial activity of trunk bark of Alstonia scholaris. Asian J Pharm Clin
Res. 2010; 3(4):46-7. https://www.researchgate.net/publication/262413327_

[33] Bag A, Bhattacharyya SK, Pal NK, Chattopadhyay RR. In vitro antibacterial potential of Eugenia jambolana seed extracts against multidrug-resistant human bacterial pathogens. Microbiol Res. 2012; 167(6):352-7. [DOI:10.1016/j. micres.2012.02.005] [PMID]

[34] Cowan MM. Plant products as antimicrobial agents. Clin Microbiol Rev. 1999; 12(4):564-82. [DOI:10.1128/ CMR.12.4.564] [PMID] [PMCID]

[35] Dewanjee S, Maiti A, Majumdar R, Majumdar A, Mandal SC. Evaluation of antimicrobial activity of hydroalcoholic extract Schima wallichii bark. Pharmacologyonline. 2008; 1:523-8. https://pharmacologyonline.silae.it/files/archives/2008/vol1/50_Dewanjee.pdf

[36] Testai L, Chericoni S, Calderone V, Nencioni G, Nieri P, Morelli I, et al. Cardiovascular effects of Urtica dioica L.(Urticaceae) roots extracts: in vitro and in vivo pharmacological studies. J Ethnopharmacol. 2002; 81(1):105-9. [DOI:10.1016/S0378-8741(02)00055-7]

[37] Obertreis B, Giller K, Teucher T, Behnke B, Schmitz H. Anti-inflammatory effect of Urtica dioica folia extract in comparison to caffeic malic acid. Arzneimittelforschung. 1996; 46(1):52-6. [PMID]

[38] Ibrahim D, Chahardehi AM, Sulaiman SF. Effects of butanol extract of Urtica dioica on MRSA: structural degeneration study. J Appl Biol Sci. 2013; 7(3):31-6. http:// www.jabsonline.org/index.php/jabs/article/view/357

[39] Heidary M, Hashemi A, Goudarzi H, Khoshnood S, Roshani M, Azimi H, et al. The antibacterial activity of Iranian plants extracts against metallo beta-lactamase producing Pseudomonas aeruginosa strains. J Paramed Sci. 2016; 7(1):13-9. https:// doi.org/10.22037/jps.v7i1.11203

[40] Bakht J, Shaheen S, Shafi M. Antimicrobial potentials of Mentha longifolia by disc diffusion method. Pak J Pharm Sci. 2014; 27(4):939-45. https://web.b.ebscohost.com/abs tract?direct $=$ true $\&$ profile $=$ ehost $\&$ scope $=$ site\&authtype $=c$ rawler\&jrnl=

[41] Hajlaoui H, Snoussi M, Jannet HB, Mighri Z, Bakhrouf A. Comparison of chemical composition and antimicrobial activities ofMentha longifolia L. ssp. longifolia essential oil from two Tunisian localities (Gabes and Sidi Bouzid). Ann Microbiol. 2008; 58(3):513. [DOI:10.1007/BF03175551]

[42] rema P. In vitro antagonistic activity of a probiotic Lactobacillus plantarum against water borne pathogens. Int J Pharm Phar Sci. 2013; 5(4):175-8. https:/ / www.researchgate.net/ publication/286795274_

[43] Venkatesan S, Kirithika M, Roselin I, Ganesan R, Muthuchelian K. Comparative invitro and invivo study of three probiotic organisms, Bifidobacterium sp., Lactobacillus $\mathrm{sp} ., \mathrm{S}$. cerevisiae and analyzing its improvement with the supplementation of prebiotics. ICHNOS. 2012; 2:94-106. http://ijpaes.com/admin/php/uploads/163_pdf.pdf

[44] Badirzadeh A, Heidari-Kharaji M, Fallah-Omrani V, Dabiri H, Araghi A, Salimi Chirani A. Antileishmanial activity of Urtica dioica extract against zoonotic cutaneous leishmaniasis. PLOS Negl Trop Dis. 2020; 14(1):e0007843. [DOI:10.1371/journal.pntd.0007843] [PMID] [PMCID] 
[45] Al-ani SA, Al-Shahwany AW. Study the Effect of Some Methanolic and Aqueous Traditional Plants Extracts on Probiotic Bacteria. Iraqi J Sci. 2018; 59(3B):1396-408. http:/ / scbaghdad.edu.iq/eijs/index.php/eijs/article/view/475 